\title{
Genetic Variations of Selected Genes Using Target Deep Sequencing in Colorectal Cancer Patients
}

Eman E Farghal ${ }^{1,2 \#}$, Marwa H Saied ${ }^{3 \#}$, Fatma M Ghaith ${ }^{1}$, Gamal I Moussa ${ }^{2,7}$, Gehan El-Sharnobi' ${ }^{1}$, Samah M Soliman $^{2,5}$, Hesham Tawfik ${ }^{6}$, Omnia Abdelfattah ${ }^{6}$, Enas A Abdul-Baki ${ }^{2,4}$, Fatma Gharib ${ }^{6}$, Lamis Mohamed ${ }^{6}$, Mohamed R El- Shanshory ${ }^{2,8}$, Amira Y Abdelnaby ${ }^{1,2}$, Mohamed L Salem2,4, Mona Watany ${ }^{1,2}$, Abdel Aziz A Zidan ${ }^{2,9}$, Yahia S Abdou ${ }^{10}$ and Said M Abdou ${ }^{1,2 * *}$

${ }^{1}$ Department of Clinical Pathology, Faculty of Medicine, Tanta University, Tanta, Egypt

${ }^{2}$ Genomic Signature Cancer Centre, Next Generation Sequencer Unit, Tanta University Global Educational Hospital, Tanta University, Tanta, Egypt

${ }^{3}$ Department of Clinical Pathology, Faculty of Medicine, Alexandria University, Alexandria, Egypt

${ }^{4}$ Department of Zoology, Division of Immunology and Biotechnology, Faculty of Science, Tanta University, Tanta, Egypt

${ }^{5}$ Department of Tropical Medicine, Faculty of Medicine, Tanta University, Tanta, Egypt

${ }^{6}$ Department of Clinical Oncology, Faculty of Medicine, Tanta University, Tanta, Egypt

${ }^{7}$ Department of Surgery, Faculty of Medicine, Tanta University, Tanta, Egypt

${ }^{8}$ Department of Paediatrics, Faculty of Medicine, Tanta University, Tanta, Egypt

${ }^{9}$ Department of Zoology, Faculty of Science, Damanhur University, Damanhur, Egypt

${ }^{10}$ Department of Medicine, Ain Shams University, Egypt

"First and second authors equally contributed in this work

\section{Abstract}

Background: Colorectal carcinoma (CRC) is a burden problem in a developing country like Egypt since patients are usually admitted in late stage with bad prognosis and short overall survival. Because of genetic predisposition of CRC and introduction of advanced molecular techniques, efforts are directed to screen for potential pathogenic or disease-causing variants in CRC patients

Methods: DNA was isolated from formalin fixed paraffin embedded tissue sections collected from 24 CRC confirmed diagnosed patients. TruSight CRC panel (Illumina) was used for detection of different variants in 15 genes. The generated reads were obtained from Illumina Miseq were clustered into single nucleotide polymorphism (SNPs) and small insertions/deletions (Indels). Further pathogenic variants with somatic and germline mutations were identified according to the recommended criteria. Some CRC patients were subjected to anti-EGFR target therapy.

Results: Most of the variants were detected in TP53 gene 140 variants (65\%); 105 short deletions none of them was pathogenic, 29 missense mutations and 6 SNPs at splicing sites. Next, ERBB2 has got 17 variants (8.8\%) (missense and splicing), 8 of them were damaging disease causing variants. Besides, 16 pathogenic variants were identified in 12 patients ( 6 in TP53 and 7 in KRAS). Some pathogenic variants were not reported before in CRC e.g. TP53 C>A, rs121912654, Val157Phe. Additionally, patients carried different KRAS wild mutations showed variable response to anti-EGFR target therapy.

Conclusion: The most affected pathway in CRC was TP53 pathway followed by ERBB2, NRAS, KRAS and $P I K 3 C A$ genes. Variable response to target therapy suggested dependence on the type of pathogenic variant identified, also a possible role of ERBB2 which had a significant variant frequency.

Keywords: Colorectal carcinoma; Trusight next generation sequencing; Molecular diagnosis

\section{Introduction}

Colorectal cancer (CRC) is considered the third most common tumour and the fourth leading cause of cancer-related mortality worldwide. Its incidence will be increased by $60 \%$ by the year 2030 [1]. At initial diagnosis, $25 \%$ of CRC patients present with metastasis and $50 \%$ will develop metastasis after diagnosis [2]. Many factors contributed to the development of CRC including genetic factors [3] and environmental factors such as diet and lifestyle [4].

Genetic alteration is a common feature of CRC ranging from small molecular changes such as point mutations or small indels to chromosomal copy number variation or translocation [5]. RAS status was mandatory to be examined before the use of anti-EGFR therapy as recommended by ESMO guidelines 2106. Also, patients carry BRAF mutations might not respond to anti-EGFR therapy [6]. Beside the RAS/ RAF, MAP kinase pathway, TP53 and the PI3K/Akt/mTOR signalling cascade are critical. The process of CRC development is an interplay between suppression of some tumor suppressor genes (TSGs) including the key TSG i.e. TP53 and activation of some oncogenes such as KRAS,
NRAS. The prevalence rate of TP53 mutation in Arab population is $52.5 \%$ compared to $47.5 \%$ in matched Western population [7]. TP53 mutations have roles in determining progression, invasiveness and also metastasis of CRC. So, CRC patients with mutant TP53 have more progressive phenotype and poorer survival than those with TP53 wild type [8]. The phosphatidylinositol 3-kinase/Akt/mammalian target of

*Corresponding author: Said M. Abdou, MD, Department of Clinical Pathology, Faculty of Medicine, Tanta University, Executive Director, Genomic Signature Cancer Centre, Next Generation Sequencer Unit, Tanta University Global Educational Hospital, Tanta University, Egypt, Tel: 20 33179280402; E-mail: saidmohamedgeda@gmail.com

Received September 18, 2017; Accepted October 16, 2017; Published October 20, 2017

Citation: Farghal EE, Saied MH, Ghaith FM, Moussa GI, El-Sharnobi G, et al (2017) Genetic Variations of Selected Genes Using Target Deep Sequencing in Colorectal Cancer Patients. J Cancer Sci Ther 9: 683-689. doi:10.4172/19485956.1000492

Copyright: () 2017 Farghal EE, et al. This is an open-access article distributed under the terms of the Creative Commons Attribution License, which permits unrestricted use, distribution, and reproduction in any medium, provided the original author and source are credited. 
rapamycin (PI3K/Akt/mTOR) signalling pathway has pivotal roles in cell proliferation, apoptosis, survival and metastasis [9]. The effects of PI3K are mediated by AKT. One of the downstream targets of AKT is mTOR which controls angiogenesis. Activation of PI3K/Akt $/ \mathrm{mTOR}$ has been reported in the development and progression of CRC [10].

Next-generation sequencing (NGS) technology has the advantage of parallel deep sequencing of genetic mutations in multiple genes in patients simultaneously [11]. Targeted sequencing is a good clinical application of NGS technology since it directed to increase the coverage of read depth of hotspot mutations through localizing the number of genes of interest examined with maintaining the number of bases sequenced [12]. Therefore, we aimed in this study to screen for potential pathogenic variants in Egyptian CRC patients in different stages of the disease.

\section{Materials and Methods}

Formalin fixed paraffin embedded tissues (FFPE) samples that were obtained from 24 CRC patients, who were referred to Tanta Main University hospital between January 2016 and June 2017. This study was approved by Tanta Ethics Committee of Faculty of Medicine. Informed consents were obtained from all patients. The age distribution of all patients ranged from 30 to 75 years with a median age of 55 years. The clinicopathological data of patients are summarized in Table 1. DNA was extracted from FFPE tissue samples using QIAamp DNA Mini Kit (QIAGEN, Hilden, Germany). The concentration of DNA was determined using the Denovix fluorimeter (AGBL, USA).

\section{Trusight tumor 15 panel illumina CRC panel}

We sequenced patient's DNA using the Trusight Tumor 15 panel

\begin{tabular}{|c|c|}
\hline \multicolumn{2}{|c|}{ Age (years) } \\
\hline Median (range) & $55.0(30.0-75.0)$ \\
\hline \multicolumn{2}{|c|}{ Gender } \\
\hline Female & $10(41.7 .0 \%)$ \\
\hline Male & $14(58.3 \%)$ \\
\hline \multicolumn{2}{|c|}{ Primary tumor location } \\
\hline Right colon & $11(45.8 \%)$ \\
\hline Transverse colon & $3(12.5 \%)$ \\
\hline Left colon & $3(12.5 \%)$ \\
\hline Sigmoid colon & $3(12.5 \%)$ \\
\hline Recto sigmoid colon & $1(4.2 \%)$ \\
\hline Rectum & $3(12.5 \%)$ \\
\hline \multicolumn{2}{|c|}{ Histology } \\
\hline Conventional adenocarcinoma & $21(87.5 \%)$ \\
\hline Signet ring cell adenocarcinoma & $3(12.5 \%)$ \\
\hline \multicolumn{2}{|c|}{ Growth pattern } \\
\hline Ulcerative & $17(70.8 \%)$ \\
\hline Fungating & $4(16.7 \%)$ \\
\hline Infilterative & $2(8.2 \%)$ \\
\hline Caulifiower mass & $1(4.2 \%)$ \\
\hline \multicolumn{2}{|c|}{ TNM stage } \\
\hline 1 & 0 \\
\hline II & $12(50 \%)$ \\
\hline III & $6(25 \%)$ \\
\hline IV & $6(25 \%)$ \\
\hline \multicolumn{2}{|c|}{ Baseline CEA and CA19-9 (ng/mL) } \\
\hline High & $4(16.7 \%)$ \\
\hline Normal & $20(83.3 \%)$ \\
\hline
\end{tabular}

Table 1: Clinicopathological criteria of CRC patients.
(Illumina, San Diego, CA, USA) that contains 15 genes suspected to have roles in cancer predisposition; TP53, AKT1, BRAF, EGFR, ERBB2, FOXL2, GNA11, GNAQ, KIT, KRAS, MET, NRAS, PDGFRA, PIK3CA and RET. Twelve genes showed coverage of $95 \%$ ( $\geq 20$ reads). In these genes, the mean read coverage was $93.5 \%$ of bases covered at $\geq 500 \times$ exonic and essential splice sites regions covered at $\geq 20$ reads. Only, NRAS, RET and GNA11 showed coverage less than $95 \%$ ( $\leq 20$ reads). For library preparation, Trusight panel DNA library preparation protocol (Illumina) was used [13].

\section{Bioinformatic Analysis}

The FASTQ files were generated using MiSeq Reporter (Illumina). The FASTQ files were assessed for their base quality. More than $85 \%$ of reads showed base quality higher than 30 . Next, reads were aligned to a reference genome hg19 and variants were called using Genome Analysis Toolkit (GATK). Then, VCFs were generated for further analysis by VariantStudio (Illumina). The passed filtered variants were selected for the analysis. Annotations included in VariantStudio were HGMD, ClinVar pathogenicity annotations, links to dbSNP, in addition to prediction tools such as SIFT, PolyPhen and Provean. We also used Varsome (The Human Genomic Variant Search Engine, https://varsome.com/), Genome Aggregation Database/exomes (gnomAD, ExAC) and Mutation Taster. The identified variants in this study were classified according to ACMG (American Society of Medical Genetics and Genomics) into five categories: (1) pathogenic, (2) likely pathogenic, (3) of uncertain significance (VUS), (4) likely benign and (5) benign [14].

\section{Results}

\section{Pathogenic and likely pathogenic variants in the CRC cohort}

Sixteen pathogenic and likely pathogenic variants were identified in 12 patients, which account for $50 \%$ of patients (Table 2). All of those variants were single nucleotide polymorphism (SNPs); 7 SNPs in TP53 gene, 6 SNPs in KRAS, 1 SNP in BRAF and 2 SNPs in PIK3CA (Table 2).

TP53 pathogenic and likely pathogenic variants: Seven TP53 pathogenic/likely pathogenic variants were identified in the studied patients. There were no repeated TP53 mutations. Five out of seven TP53 mutations were germline inherited. All of these mutations were missense mutations located in three exons; 5, 7 and 8 (the commonest sites of TP53 mutations) [15]. Each exon has 2 identified mutations with one mutation found in exon 10. A pathogenic variant identified in patient ID 8 in exon 5 (C>A, rs121912654, Val157Phe), was not reported before in CRC, while it was found previously in patients with chronic lymphocytic leukemia [16] and hepatocellular carcinoma [17]. Similarly, a pathogenic variant was detected in exon 5 in patient ID 17 (C>T, rs28934578, Arg175His), is one of germline mutations detected in DNA binding domain in TP53 in solid tumors e.g. breast cancer [18]. Patient ID 17 also has got another pathogenic mutation (G>A, rs587782529, Arg337Cys) outside the common sites of TP53 mutations i.e. in exon 10. This mutation is associated with unclassical Li-Fraumeni syndrome [19]. Furthermore, exon 7 has got 2 mutations e.g. C>T, rs28934575, Gly245Ser which was previously described in CRC [20] and G>A, rs121912651, Arg248Trp which is a well-known pathogenic variant in CRC [21]. Exon 8 has got 2 pathogenic variants that are associated with Li-Fraumeni syndrome (G>A, rs149633775Arg283Cys, C>T and rs763098116- Cys277Phe) [22]. Generally, TP53 has got 29 missense mutations; 7 were reported as pathogenic, 3 with uncertain significance and the remaining missense mutations were benign/ likely benign. 
Citation: Farghal EE, Saied MH, Ghaith FM, Moussa GI, El-Sharnobi G, et al. (2017) Genetic Variations of Selected Genes Using Target Deep Sequencing in Colorectal Cancer Patients. J Cancer Sci Ther 9: 683-689. doi:10.4172/1948-5956.1000492

\begin{tabular}{|c|c|c|c|c|c|c|c|c|c|c|c|}
\hline Gene & $\begin{array}{c}\text { Case } \\
\text { no. }\end{array}$ & Exon no & $\begin{array}{l}\text { Type of } \\
\text { mutation }\end{array}$ & Variant & Heterogeneity & Inheritance & SIFT & Provean & $\begin{array}{l}\text { Amino acid } \\
\text { substitution }\end{array}$ & $\begin{array}{c}\text { Age at diagnosis } \\
\text { (Years) }\end{array}$ & Reference \\
\hline TP53 & 17 & Exon 10 & SNP & $G>G / A$ & Het & Germline & Damaging & Damaging & p.Arg337Cys & 75 & rs587782529 \\
\hline TP53 & 18 & Exon 8 & SNP & $G>G / A$ & Het & $\mathrm{N} / \mathrm{A}$ & Damaging & Damaging & p.Arg283Cys & 48 & rs149633775 \\
\hline TP53 & 5 & Exon 8 & SNP & $\mathrm{C}>\mathrm{C} / \mathrm{T}$ & Het & Germline & Damaging & Damaging & Cys277Phe & 64 & rs763098116 \\
\hline TP53 & 4 & Exon 7 & SNP & $G>G / A$ & Het & Germline & Damaging & Damaging & p.Arg248Trp & 55 & rs121912651 \\
\hline TP53 & 1 & Exon 7 & SNP & $\mathrm{C}>\mathrm{C} / \mathrm{T}$ & Het & Germline & Damaging & Damaging & Gly245Ser & 64 & rs28934575 \\
\hline TP53 & 17 & Exon 5 & SNP & $\mathrm{C}>\mathrm{C} / \mathrm{T}$ & Het & Germline & Damaging & Damaging & p.Arg175His & 75 & rs28934578 \\
\hline TP53 & 8 & Exon 5 & SNP & $\mathrm{C}>\mathrm{C} / \mathrm{A}$ & Het & Somatic & Damaging & Damaging & Val157Phe & 75 & rs121912654 \\
\hline KRAS & 10 & Exon 4 & SNP & $\mathrm{C}>\mathrm{C} / \mathrm{T}$ & Het & Germline & Damaging & Damaging & Ala146Thr & 65 & rs121913527 \\
\hline KRAS & 20 & Exon 3 & SNP & $G>G / A$ & Het & Germline & Damaging & Damaging & p.Thr58lle & 55 & rs104894364 \\
\hline KRAS & 3 & Exon 2 & SNP & $G>G / A$ & Het & Somatic & Damaging & Damaging & Not applicable & 62 & rs397517040 \\
\hline KRAS & 5 & Exon 2 & SNP & $\mathrm{C}>\mathrm{C} / \mathrm{T}$ & Het & Somatic & Damaging & Damaging & Gly13Asp & 64 & rs112445441 \\
\hline KRAS & 16 & Exon 2 & SNP & $\mathrm{C}>\mathrm{C} / \mathrm{T}$ & Het & Somatic & Damaging & Damaging & Gly13Asp & 50 & rs112445441 \\
\hline KRAS & 4 & Exon 2 & SNP & $\mathrm{C}>\mathrm{C} / \mathrm{T}$ & Het & Somatic & Damaging & Damaging & Gly12Asp & 55 & rs121913529 \\
\hline KRAS & 11 & Exon 2 & SNP & $\mathrm{C}>\mathrm{C} / \mathrm{G}$ & Het & Somatic & Damaging & Damaging & Gly12Ala & 48 & rs121913529 \\
\hline KRAS & 8 & Exon 2 & SNP & $\mathrm{C}>\mathrm{C} / \mathrm{T}$ & Het & Somatic & Damaging & Damaging & Gly12Ser & 52 & rs121913530 \\
\hline$B R A F$ & 7 & Exon 15 & SNP & $A>A / T$ & Het & Somatic/Germline & Damaging & Damaging & Val600Glu & 60 & rs113488022 \\
\hline$B R A F$ & 19 & Exon 15 & SNP & $\mathrm{C}>\mathrm{C} / \mathrm{A}$ & Het & Somatic & Damaging & Damaging & Gly596Val & 75 & Not provided \\
\hline PIKЗCA & 4 & Exon 10 & SNP & $G>G / A$ & Het & Somatic & Damaging & Damaging & p.Glu545Lys & 55 & rs104886003 \\
\hline PIKЗCA & 16 & Exon 21 & SNP & $A>A / G$ & Het & Somatic & Damaging & Damaging & p.His1047Arg & 50 & rs121913279 \\
\hline
\end{tabular}

Table 2: Pathogenic and likely pathogenic variants in CRC patients.

KRAS pathogenic and likely pathogenic variants: Six pathogenic variants/likely pathogenic variants were identified in KRAS, 4 mutations were in exon 2 (66\%), one mutation in exon 3 and one mutation in exon 4 (Table 2). All of them were SNPs and somatically inherited. KRAS exon 2 mutations are found to be predictors of bad prognosis and resistance to anti-EGFR antibody therapy [23]. Pathogenic variant (C>T, 112445441, Gly13Asprs) was repeated in 2 patients; IDs 5 and 16. This mutation (Gly13Asprs) was associated with invasive pancreatobiliary tumors in Turkish population [24]. Pathogenic variant (rs121913529) was also identified in 2 patients; IDs 4 and 11 . This mutation, in addition to the pathogenic variant $(\mathrm{C}>\mathrm{T}$, rs121913530, Gly12Ser) were detected in patient ID 8. Both variants were shown to discriminate conventional adenoma from CRC [25]. The remaining pathogenic KRAS variants were found in exon $3(\mathrm{G}>\mathrm{A}$, rs104894364, Thr58Ile patient ID 20) and in exon 4 (C>T, rs121913527, Ala146Thr patient ID 10), both are well-known pathogenic variants in CRC [26]. Furthermore, one pathogenic variant (A>T, rs113488022, Val600Glu) was identified in $B R A F$ in patient ID 7, this mutation was found in sessile serrated polyps; precursor of CRC [26] (Table 2). Also, Patient ID 19 has got C>A, Gly596Val variant. Finally, two pathogenic variants were detected in PIK3CA; G>A rs104886003, Glu545Lys in patient ID 4, this mutation is one of the hotspots found in exon 10 that is considered a driver PIK3CA gene mutation [27]. Also, a known pathogenic PIK3CA mutation (A>G, rs121913279, His1047Arg) [21] was identified in patient ID 16. Therefore, most of pathogenic missense mutations were identified in KRAS in exon 2. Less commonly, few hotspot pathogenic variants were detected in BRAF and PIK3CA.

\section{Missense, splicing and indels mutations}

Next, total number of mutations in every gene was investigated. TP53 has got the highest number of detected mutations in 24 patients i.e. $140(65 \%)$; 105 short deletions none of them was pathogenic, 29 missense mutations and 6 SNPs at splicing sites, one of them was a disease-causing at intron 9 patient ID 22. ERBB2 was the second most common gene that had mutations (8.8\%). ERBB2 has got 11 missense mutations: one in exon 17 (Arg678Trp), patient ID 8, four variants in exon 18; (Thr686Met) patient ID 7, (Glu717Asp) patient ID 14, (Ser728Phe) patient ID 3 and (Gly732Asp) patient ID 22. All of them were predicted as damaging by SIFT and Provean. However, three neutral tolerated missense variants in exon 20 were also identified in ERBB2: Val777Leu, Gly778Asp, Val777Leu and two tolerated neutral variants in exon 26 (Pro1121Leu, p.Val1128Ile). One missense variant predicted as damaging (Ser1054Ile) was identified in exon 26 in 3 patients IDs 4, 7 and 8. In addition, ERBB2 has got 6 variants at splice site; one damaging variant (Pro699Ser) in exon 18 patient ID 1, one damaging variant (Pro1137Ala) in exon 26 patient ID 4. In addition, NRAS has got $6 \%$ of total identified variants. All ten missense mutations found in NRAS gene were of low frequency (seen in less than $10 \%$ of the reads covering a given base). Three low variant frequency mutations at the splice site were also identified; one in exon 3, two in exon 4; Gln99His patient ID 22 and Ser145Ter patient ID 19. Besides, KIT has got $3.8 \%$ of frequent detected variants; four missense mutations, three of them were predicted as damaging by SIFT and Provean; Gly432Val, Pro467Gln, Ser821Tyr, while a benign missense variant (Met541Leu) was identified. The latter mutation was repeated in patients IDs 1, 18, 22 and 2. In addition, KIT included four mutations at the splice site, one of them was predicted as damaging by SIFT and Provean in exon 17 (Asn828Lys) in patient ID 22. One variant at the splice site (exon 18, $\mathrm{G}>\mathrm{C}, \mathrm{rs} 3733542$, benign, germline) was repeated in patients IDs 1,15 , 16, 18, 21, 22 and 24. PDGFRA has also 3.8\% of the identified variants; 6 missense mutations [Met578Ile, Asn656Lys, Gly838Asp, Ala840Thr, Asn659Lys, and Ala663Asp]. Besides, PDGFRA has a repeated inactivated silent SNP (A>G rs1873778, at codon 567 (P567P) in exon 12 [28] that presents as homozygous allele (GG) in all CRC patients except in patients IDs 6, 20, 22 where the variant was heterozygous (AG). The GG allele was the most frequent similar to European Caucasian population [29]. A characteristic insertion (T>TA) in exon 18 was also found in most of patients (homozygous TA/TA in patients IDs $1,2,4,7,8,9,10,11,13,14,15,16,17,22,23$ and 24), (heterozygous T> TA, rs3830355, IVS18-50insA in patients IDs 3, 5,6, 12 and 18). Both PDGFRA exon 18 mutation and exon 12 mutation were related more to gastric and intestinal GIST (gastrointestinal tumors) more than to colonic [30]. Two splice site variants were also identified without provided amino acid substitution. Similarly, KRAS has got 8 identified mutations (3.8\%); six of them were pathogenic as mentioned before and 2 intronic SNPs. FOXL2 has 4 missense mutations Arg148Leu, 
Arg147Cys, Arg145His, and Pro116Ser. All of them were in exon 1 and predicted as damaging mutations. Furthermore, PIK3CA showed 5 missense mutations with the following amino acids substitution: Arg524Lys, Glu542Gln, Glu545Lys, Met1043Val, and His1047Arg with one disease-causing nonsense mutation: Arg992Ter (Table 3). BRAF has 2 missense pathogenic variants (Val600Glu and Gly596Val) and another one at the splice site. EGFR has got 2 missense mutations that are predicted as damaging (Gly779Cys patient ID 22 and Val819Met patient ID 19), both of them were found in exon 20. Also, 2 variants were found in splice site in EGFR; one in exon 20 (Ala822Thr) and two in intron 17. AKT1 has got only one variant at splice site: rs770565457, patient ID 17 with no clinical significance. Furthermore, two missense variants were predicted as damaging in exon 5 in GNA11; Arg210Trp in patients IDs 3, 19 and Arg213Trp in patient ID 3. Finally, MET gene has got two missense mutations; a tolerated neutral variant (Gly1102Asp) in exon 16 patient ID 3 and a damaging variant (Pro1285Leu) in exon 20 patient ID 21. One variant at splice site was also found; (Asn1209Lys) in exon 18 patient ID 3. In summary, our analysis revealed that most of investigated variants were detected in TP53 (65\%) followed by ERBB2 (8.8\%), suggesting more involvement of TP53 pathway than KRAS or PI3K pathways in Egyptian population [21].

\section{TP53 showed the highest percentage of germline inherited mutations among CRC patients}

Total of 37 mutations with known type of inheritance were identified in 24 patients. Out of these 37 mutations, 24 germline mutations were detected $(65 \%)$, most of them were in TP53 $(10 / 24=42 \%)$ followed by $\operatorname{KIT}(5 / 24=21 \%)$. Thirteen somatic/acquired mutations were identified (35\%). Most of the somatic mutations were found equally in KRAS $(4 / 13=30 \%)$ and EGFR $(4 / 13=30 \%)$. There was no significant correlation between the number of germline mutations in each patient with either lymph node metastasis $(\mathrm{P}=0.6)$ or distant metastasis $(\mathrm{P}=0.78)$. However, it was noticed that patient ID 4 has got the highest number of both germline mutations ( 5 mutations); 2 mutations in

\begin{tabular}{|c|c|c|c|c|c|c|c|c|c|c|c|c|c|c|c|}
\hline Variants & 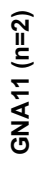 & 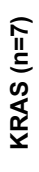 & $\begin{array}{l}\underset{\text { II }}{\text { İ }} \\
\text { 卢 }\end{array}$ & $\begin{array}{l}\text { ô } \\
\text { II } \\
\text { Е } \\
\underline{\underline{\Sigma}}\end{array}$ & $\begin{array}{l}\text { II } \\
\text { É } \\
\text { E }\end{array}$ & 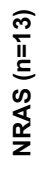 & 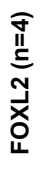 & 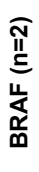 & 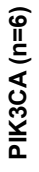 & 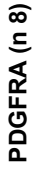 & 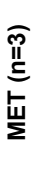 & 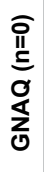 & 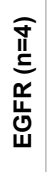 & 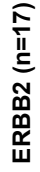 & 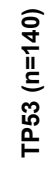 \\
\hline Deletion & 0 & 0 & 0 & 0 & 0 & 0 & 0 & 0 & 0 & 0 & 0 & 0 & 2 & 0 & 105 \\
\hline Missense & 2 & 6 & 0 & 4 & 0 & 10 & 4 & 2 & 6 & 6 & 2 & 0 & 2 & 11 & 29 \\
\hline Splicing & 0 & 1 & 1 & 4 & 1 & 3 & 0 & 1 & 0 & 2 & 1 & 0 & 2 & 6 & 6 \\
\hline
\end{tabular}

Table 3: Missense, indels, splicing variants identified in CRC patients.

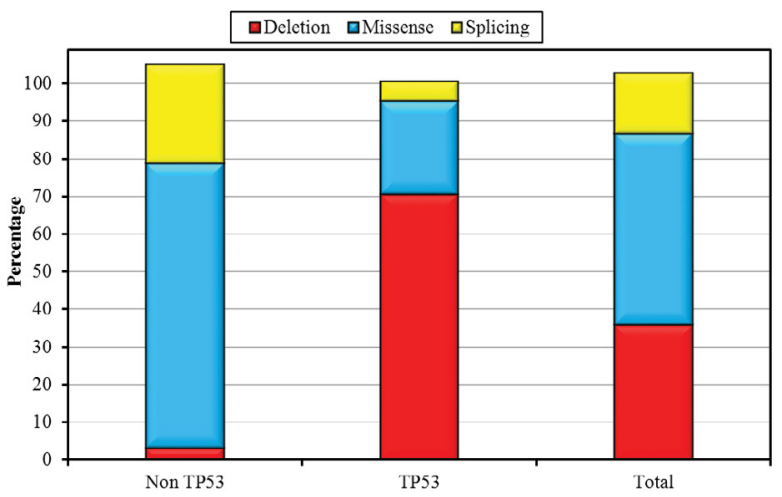

Figure 1: Comparison of variant percentage among TP53 and the other studied genes.
TP53 and one mutation in each following gene MET, PDGFRA, EGFR in addition to 4 somatic mutations; 2 in PIK3CA, one in KRAS and one in EGFR. Patient ID 4 showed the highest number also of lymph node (LN) involvement (18 LNs) with distant metastasis in liver. No CRC patients who were involved in the current study had positive family history of malignancy except patient ID 14 who was the only one who had family history of uterine, colon and breast cancer. She was 50 years at the diagnosis of CRC with 2 lymph nodes involvement with liver metastasis. Interestingly, this patient did not have a known germline pathogenic variant, but she has got a missense mutation in FOXL2 $(\mathrm{G}>\mathrm{A}$, Pro116Ser). This mutation was predicted as damaging by SIFT and Provean, and was not previously described in CRC. Family screening of this variant is recommended for that patient since this missense variant could be exist but with much less allelic frequency [31]. Patient ID 14 has got another damaging missense mutation in ERBB2 in exon 18 (G>T, Glu717Asp); this mutation could be an activating mutation that is accompanied with ERBB2 overexpression [32]. Another interesting finding was related to patient ID 9; who was the only case with bone marrow metastasis. Since bone metastasis is extremely rare in CRC [33], we searched for associated variants that might predispose to this sign. No pathogenic variants were detected, besides no characteristic variants were unique to patient ID 9. For instance, G>A, rs1050171 was identified in exon 20; this genotype is a predictor of bad responsiveness to anti-EGFR therapy in metastatic CRC [34]. Also, C $>\mathrm{T}$, rs41736 in exon 20 in $M E T$ was also found but with no previous association with bone metastasis (Figure 1) Therefore, cytopatholological examination from bone metastasis is very recommended since it is expected to have distinct mutations from that of primary tumour [35]. Concisely, most of mutations detected were germline $(65 \%)$, commonly present in TP53 (42\%) while the somatic mutations (35\%) were found mainly in two oncogenes i.e. KRAS and EGFR

\section{Patients showed different response to anti-EGFR target therapy}

Finally, we tried to correlate the identified variants with target therapy. Not all patients were subjected to anti-EGFR target therapy since this therapy should be covered by patient's insurance. Patients IDs $4,8,12,17$ and 24 were subjected to avastin. Patients IDs 4,17 and 24 were good responders with stable disease. Patient ID 4 has got TP53-KRAS- PIK3CA pathogenic variants: TP53 mutation was G>A [rs121912651, Arg248Trp] in exon 7, KRAS pathogenic variant was C>T rs121913529 Gly12Asp in exon 2. The latter mutation is one of KRAS mutations that predict anti-EGFR response [36] which appeared in our study to be sensitive to avastin with stability of the disease after applying the drug. The PIK3CA pathogenic variant was $\mathrm{G}>\mathrm{A}$ rs104886003 Glu545Lys. For the second good responder; patient ID 17 she has got two pathogenic variants in TP53; G>A rs587782529 Arg337Cys in exon 10 and $\mathrm{C}>\mathrm{T}$ rs28934578 Arg175His in exon 5. However, patient ID 24 did not have any pathogenic variant and the identified variants in this patient were benign, tolerated by SIFT and neutral by Provean predictors. Nevertheless, patients ID 8 and 12 showed no response and died. For patient ID 8, two pathogenic variants were found; TP53 C>A, rs121912654 Val157Phe in exon 5 and KRAS C>T rs121913530 Gly12Ser in exon 2. However, for patient ID 12 no pathogenic variant was detected only a homozygous TT rs41736 was found in exon 20 in MET gene; This germline mutation was reported in CRC and siblings with $18 \%$ allelic frequency [37]. In brief, most of CRC patients who have different pathogenic variants showed variable response to anti-EGFR therapy.

\section{Discussion}

Basically, CRC is a disease that results from an interplay between 
common and rare variants with different penetrance [38]. This genetic predisposition will assist in screening high-risk family for CRC. Multiple genetic pathways are involved in the pathogenesis of CRC e.g. WNT signalling pathway (adenomatous polyposis coli gene (APC), BubR1), RAS pathway (KRAS, BRAF, mitogen-activated protein kinase $M A P K), P 53$ pathway with the involved genes: PI3KCA [39]. With the introducing of advanced molecular techniques e.g. next-generation sequencing multiple genetic defects were investigated through genomewide studies [40-42]. In the present study, we were able to investigate 15 genes generally affected in CRC through TruSight sequencing panel (Illumina). We found 16 pathogenic variants in 12 patients $(50 \%$ of total patients). Six of the patients participating in this study had TP53 missense pathogenic variants $(25 \%)$ which are comparable to other population $(33 \%)$ [43]. However, no one of those six patients met classical Li-Fraumni syndrome [44] or Li-Fraumeni-like criteria [45]. It was reported that TP53 germline mutations were found in $4-5 \%$ in Li-Fraumni syndrome (LFS). However, presence of TP53 mutations with absence of personal and family history that met LFS criteria was also observed in previous studies [46,47]. Consequently, TP53 had the highest number of investigated mutations including missense, short deletions and splicing mutations as mentioned in results sections; I. a, II and III. Most of them were germline, meaning potentially early onset of the incidence of CRC. Therefore, it is highly recommended to families of those patients to be subjected to direct DNA sequencing of TP53 exons 2-11 as a screening tool [48]. Additionally, eleven patients were found to have KRAS mutations $(\sim 46 \%)$, which is matching with the published percentage (30\% to 50\%) [49,50]. The importance of KRAS mutations are its impact on anti-EGFR target therapy in metastatic colon cancer, with better overall survival for patients carry wild KRAS mutation than mutant KRAS [51]. Downregulation of KRAS subsequenct overexpression of EGFR inhibits PI3K-ERK signalling pathways. Patient ID 4 carried one of the common wild KRAS mutation in codon12 (G>A, Gly12Asp, G12D, rs121913529) [52]. This patient showed good response to anti EGFR target therapy. That codon 12 KRAS mutation was also detected in patient ID 11. Another common codon 12 KRAS wild mutation (Gly12Ser) was found in patient ID 8 with progression and subsequent death in spite of pantimumab target therapy. Codon 13 wild KRAS common mutation (Gly13Asp) was detected in patient's ID 5 and 16. Unfortunately, both patients were not subjected to anti-EGFR therapy in order to follow the drug response. Interestingly, patient ID 20 had a wild KRAS mutation outside the hotspot codons (Ala146Thr); this mutation confers phenotype similar to mutations in the hotspot codons thus a similar response to chemotherapy [53]. Another modulator of $M A P K$ pathway is BRAF gene. The coexistence of both KRAS and BRAF is uncommon in CRC patients. In the present study, patients ID 3 and 19 carried 2 different $B R A F$ mutations: Val600Glu (A>T, rs113488022) [54] and Gly596 Val (C>A), both variants are pathogenic with different molecular, pathological characteristics and clinical outcomes [55]. These two patients could be benefit from anti-BRAF in combination with anti-EGFR or anti-MAPK [56]. Overall, BRAF mutations (mutant or wild) have worse overall survival than KRAS mutation carriers. Finally, PIK3CA, which plays important role in $M A P K$ pathway, has got pathogenic missense variants in patient ID $4(\mathrm{G}>\mathrm{A}$, rs104886003, Glu545Lys) and patient ID 16 (A>G, rs121913279, His1047Arg,). Both variants are PIK3CA hotspot somatic mutations [57] with good response to cetuximab [25]. Interestingly, patient ID 4 is a very good example of a possible interplay between pathways of TP53, KRAS and $P I 3 K$. These patients have 3 pathogenic variants; one in each previous gene and showed a good respond to anti-EGFR therapy. However, patient ID 8, who had also 2 pathogenic variants in P53 and KRAS, was bad responder and died. This likely correlation between previous variants could be based on potential molecular cross-talk between different pathways since activation of AKT inhibits TP53-mediated apoptosis. In addition, mutant KRAS antagonizes the downstream of $P I 3 K$ signalling in colon cancer cell lines [58]. Remarkably, thirteen patients (54\% of patients) included in the present study had 11 ERBB2 missense mutations with amino acid substitutions; 8 of them were predicted as damaging disease-causing variants. These variants may be associated with $E R B B 2$ protein overexpression, thus potential response to anti-Her2/neu (trastuzumab) in combination with other agents e.g. cetuximab and pertuzumab $[59,60]$.

\section{Conclusion}

To our knowledge, this is the first CRC study performed in Egypt using Trusight colorectal cancer panel. Although the relative small number of patients involved, this study is considered a good start to know the potential variants found in Egypt and the affected genes to be more focused and investigated.

\section{Acknowledgment}

Acknowledgment is to Genetic Signature Cancer Center, Tanta University, Egypt

\section{Funding}

This work was funded by grants from Tanta University and Ministry of Higher Education, Egypt

\section{References}

1. Ferlay J, Steliarova-Foucher E, Lortet-Tieulent J, Rosso S, Coebergh JW, et al. (2013) Cancer incidence and mortality patterns in Europe: Estimates for 40 countries in 2012. Eur J Cancer 49: 1374-403.

2. Van Cutsem E, Cervantes A, Nordlinger B, Arnold D, Group EGW (2014) Metastatic colorectal cancer: ESMO clinical practice guidelines for diagnosis treatment and follow-up. Ann Oncol 3: 1-9.

3. Fearon ER (2011) Molecular genetics of colorectal cancer. Annu Rev Pathol 6: 479-507.

4. Huxley RR, Ansary-Moghaddam A, Clifton P, Czernichow S, Parr CL, et al (2009) The impact of dietary and lifestyle risk factors on risk of colorectal cancer: A quantitative overview of the epidemiological evidence. Int J Cancer 125: $171-180$.

5. Kim TM, Lee SH, Chung YJ (2013) Clinical applications of next-generation sequencing in colorectal cancers. World J Gastroenterol 19: 6784-6793.

6. Van Cutsem E, Cervantes A, Adam R, Sobrero A, Van Krieken JH, et al. (2016) ESMO consensus guidelines for the management of patients with metastatic colorectal cancer. Ann Oncol 27: 1386-1422.

7. Al-Shamsi HO, Jones J, Fahmawi Y, Dahbour I, Tabash A, et al. (2016) Molecular spectrum of KRAS, NRAS, BRAF, PIK3CA, TP53, and APC somatic gene mutations in Arab patients with colorectal cancer: Determination of frequency and distribution pattern. J Gastrointest Oncol 7: 882-902.

8. Li XL, Zhou J, Chen ZR, Chng WJ (2015) P53 mutations in colorectal cancer-molecular pathogenesis and pharmacological reactivation. World $\mathrm{J}$ Gastroenterol 21: 84-93.

9. Johnson SM, Gulhati P, Rampy BA, Han Y, Rychahou PG, et al. (2010) Novel expression patterns of PI3K/Akt/mTOR signalling pathway components in colorectal cancer. J Am Coll Surg 210: 767-776.

10. Wang H, Duan L, Zou Z, Li H, Yuan S, et al. (2014) Activation of the PI3K/Akt/ $\mathrm{mTOR} / \mathrm{p} 70 \mathrm{~S} 6 \mathrm{~K}$ pathway is involved in S100A4-induced viability and migration in colorectal cancer cells. Int J Med Sci 11: 841-849.

11. Moorcraft SY, Gonzalez D, Walker BA (2015) Understanding next generation sequencing in oncology: A guide for oncologist. Crit Rev Oncol Hematol 96: 469-474

12. Han SW, Kim HP, Shin JY, Jeong EG, Lee WC, et al. (2013) Targeted sequencing of cancer-related genes in colorectal cancer using next-generation sequencing. PloS ONE 8: e64271. 
Citation: Farghal EE, Saied MH, Ghaith FM, Moussa GI, El-Sharnobi G, et al. (2017) Genetic Variations of Selected Genes Using Target Deep Sequencing in Colorectal Cancer Patients. J Cancer Sci Ther 9: 683-689. doi:10.4172/1948-5956.1000492

13. Mannan AU, Singh J, Lakshmikeshava R, Thota N, Singh S, et al. (2016) Detection of high frequency of mutations in a breast and/or ovarian cance cohort: implications of embracing a multi-gene panel in molecular diagnosis in India J Hum Genet 61: 515-522.

14. Richards S, Aziz N, Bale S, Bick D, Das S, et al. (2015) Standards and guidelines for the interpretation of sequence variants: $A$ joint consensus recommendation of the American College of Medical Genetics and Genomics and the Association for Molecular Pathology. Genet Med 17: 405-424.

15. Olivier M, Hollstein M, Hainaut P (2010) TP53 mutations in human cancers: origins, consequences, and clinical use. Cold Spring Harb Perspect Biol 2 a001008.

16. Sutton LA, Ljungstrom V, Mansouri L, Young E, Cortese D, et al. (2015) Targeted next-generation sequencing in chronic lymphocytic leukemia: A high-throughput yet tailored approach will facilitate implementation in a clinical setting. Haematologica 100: 370-376.

17. Bressac B, Kew M, Wands J, Ozturk M (1991) Selective G to T mutations of p53 gene in hepatocellular carcinoma from southern Africa. Nature 350: 429-431.

18. Damineni S, Rao VR, Kumar S, Ravuri RR, Kagitha S, et al. (2014) Germline mutations of TP53 gene in breast cancer. Tumour Biol 35: 9219-9227.

19. Luca JW, Strong LC, Hansen MF (1998) A Germline missense mutation R337C in Exon 10 of the human p53. Gene Hum Mutat 1: S58-S61.

20. George Priya Doss C, Rajasekaran R, Arjun P, Sethumadhavan R (2010) Prioritization of candidate SNPs in colon cancer using bioinformatics tools: An alternative approach for a cancer biologist. Interdiscip Sci 2: 320-46.

21. Chang YC, Chang JG, Liu TC, Lin CY, Yang SF, et al. (2016) Mutation analysis of 13 driver genes of colorectal cancer-related pathways in Taiwanese patients. World J Gastroenterol 22: 2314-2325.

22. Dorschner MO, Amendola LM, Turner EH, Robertson PD, Shirts BH, et al (2013) Actionable, pathogenic incidental findings in 1,000 participants' exomes. Am J Hum Genet 93: 631- 640 .

23. Hocking CM, Price TJ (2014) Panitumumab in the management of patients with KRAS wild-type metastatic colorectal cancer. Therap Adv Gastroenterol 7:20-37.

24. Egeli U, Ak S, Cecener G, Tunca B, Tezcan G, et al. (2016) Impact of 3'UTR variation patterns of the KRAS gene on the aggressiveness of pancreatobiliary tumors with the KRAS G13D mutation in a Turkish population. Pancreatology 16: $677-686$.

25. Geissler AL, Geissler M, Kottmann D, Lutz L, Fichter CD, et al. (2017) ATM mutations and E-cadherin expression define sensitivity to EGFR-targeted therapy in colorectal cancer. Oncotarget 8: 17164-17190.

26. Peeters M, Douillard JY, Van Cutsem E, Siena S, Zhang K, et al. (2013) Mutant KRAS codon 12 and 13 alleles in patients with metastatic colorectal cancer: Assessment as prognostic and predictive biomarkers of response to panitumumab. J Clin Oncol. 31: 759-765.

27. Winkler EC, Wiemann S (2016) Findings made in gene panel to whole genome sequencing: Data, knowledge, ethics-and consequences? Expert Rev Mol Diagn 16: 1259-1270.

28. Veits L, Schupfner R, Hufnagel P, Penzel R, Freitag J, et al. (2014) KRAS, EGFR, PDGFR-alpha, KIT and COX-2 status in carcinoma showing thymuslike elements (CASTLE). Diagn Pathol 9: 116.

29. Estevez-Garcia P, Castano A, Martin AC, Lopez-Rios F, Iglesias J, et al (2012) PDGFR alpha/beta and VEGFR2 polymorphisms in colorectal cancer: Incidence and implications in clinical outcome. BMC Cancer 12: 514.

30. Lasota J, Dansonka-Mieszkowska A, Sobin LH, Miettinen M (2004) A grea majority of GISTs with PDGFRA mutations represent gastric tumors of low or no malignant potential. Lab Invest 84: 874-83.

31. Nicolas Richard MD, Coudray N, Ballandonne C, Gilbert-Dussardier B, Kottler ML (2017) Somatic mosaicism of GNAS mutation in pseudohypoparathyroidism 1A: A new challenge for genetic counselling. endocrine society.

32. Kavuri SM, Jain N, Galimi F, Cottino F, Leto SM, et al. (2015) HER2 activating mutations are targets for colorectal cancer treatment. Cancer Discov 5: 832-41.

33. Baek SJ, Hur H, Min BS, Baik SH, Lee KY, et al. (2016) The characteristics of bone metastasis in patients with colorectal cancer: A long-term report from a single institution. World J Surg 40: 982-986.
34. Bonin S, Donada M, Bussolati G, Nardon E, Annaratone L, et al (2016) A synonymous EGFR polymorphism predicting responsiveness to anti-EGFR therapy in metastatic colorectal cancer patients. Tumor Biology 37: 7295-7303.

35. Yim E, An HJ, Cho U, Kim Y, Kim SH, et al. (2016) Two different KIT mutations may lead to different responses to imatinib in metastatic gastrointestinal stromal tumor. Korean J Intern Med. p. 295

36. Chan E (2017) KRAS c.35G>A [G12D) mutation in colorectal cancer. My cancer genome.

37. Neklason DW, Burt RW (2014) Methods of detecting hereditary cancer predisposition.

38. Hahn MM, De Voer RM, Hoogerbrugge N, Ligtenberg MJ, Kuiper RP, et al. (2016). The genetic heterogeneity of colorectal cancer predispositionguidelines for gene discovery. Cell Oncol (Dordr) 39: 491-510.

39. Colussi D, Brandi G, Bazzoli F, Ricciardiello L (2013) Molecular pathways involved in colorectal cancer: Implications for disease behavior and prevention. Intl J Mol Sci 14: 16365-16385.

40. Broderick P, Carvajal-Carmona L, Pittman AM, Webb E, Howarth K, et al. (2007) A genome-wide association study shows that common alleles of SMAD7 influence colorectal cancer risk. Nat genet 39: 1315-1317.

41. Peters U, Jiao S, Schumacher FR, Hutter CM, Aragaki AK, et al. (2013) Identification of genetic susceptibility loci for colorectal tumors in a genomewide meta-analysis. Gastroenterology 144: 799-807.

42. Whiffin N, Hosking FJ, Farrington SM, Palles C, Dobbins SE, et al. (2014) Identification of susceptibility loci for colorectal cancer in a genome-wide metaanalysis. Human Mol Genet 23: 4729-4737.

43. Susswein LR, Marshall ML, Nusbaum R, Vogel Postula KJ, Weissman SM, et al. (2016) Pathogenic and likely pathogenic variant prevalence among the first 10,000 patients referred for next-generation cancer panel testing. Genetics in medicine: Official Journal American College of Medical Genetics 18: 823-832.

44. Li FP, Fraumeni JF, Jr. Mulvihill JJ, Blattner WA, Dreyfus MG, et al. (1988) A cancer family syndrome in twenty-four kindreds. Cancer Res 48: 5358-5362.

45. Birch JM, Hartley AL, Tricker KJ, Prosser J, Condie A, et al. (1994) Prevalence and diversity of constitutional mutations in the p53 gene among $21 \mathrm{Li}$-Fraumen families. Cancer Res 54: 1298-304.

46. Stoffel EM, Kastrinos F (2014) Familial colorectal cancer, beyond Lynch syndrome. Clinical gastroenterology and hepatology: The Official Clinical Practice Journal of the American Gastroenterological Association 12: 1059-68.

47. Yurgelun MB, Masciari S, Joshi VA, Mercado RC, Lindor NM, et al. (2015) Germline TP53 mutations in patients with early-onset colorectal cancer in the colon cancer family registry. JAMA Oncology 1: 214-221.

48. Robles Al, Harris CC (2010) Clinical outcomes and correlates of TP53 mutations and cancer. Cold Spring Harbor Perspectives in Biology 2: a001016.

49. Bell SM, Scott N, Cross D, Sagar P, Lewis FA, et al. (1993) Prognostic value of p53 overexpression and c-Ki-ras gene mutations in colorectal cancer. Gastroenterology 104: 57-64

50. De Roock W, Piessevaux H, De Schutter J, Janssens M, De Hertogh G, et al. (2007) KRAS wild-type state predicts survival and is associated to early radiological response in metastatic colorectal cancer treated with cetuximab. Ann Oncol 19: 508-515.

51. Lievre A, Bachet JB, Le Corre D, Boige V, Landi B, et al. (2006) KRAS mutation status is predictive of response to cetuximab therapy in colorectal cancer Cancer Res 66 :3992-3995.

52. Licar A, Cerkovnik P, Ocvirk J, Novakovic S (2010) KRAS mutations in Slovene patients with colorectal cancer: Frequency, distribution and correlation with the response to treatment. Int J Oncol 36: 1137-1144.

53. Higgs R (2010) Screening: A re-evaluation of KRAS mutational 'hotspots' Nature Reviews Clinical Oncology 7: 242.

54. Qiu J, Compagnone M, Laibe S, Lagarde A, Goncalves A, et al. (2011) BRAF p. Val600Glu (V600E) somatic mutation is mainly associated with MSS phenotype in metastatic colorectal cancer. Cancer Genomics Proteomics 8: 15-28.

55. Cremolini C, Di Bartolomeo M, Amatu A, Antoniotti C, Moretto R, et al. (2015) BRAF codons 594 and 596 mutations identify a new molecular subtype of metastatic colorectal cancer at favourable prognosis. Annals of oncology: Official Journal of the European Society for Medical Oncology 26: 2092-2097. 
Citation: Farghal EE, Saied MH, Ghaith FM, Moussa GI, El-Sharnobi G, et al. (2017) Genetic Variations of Selected Genes Using Target Deep Sequencing in Colorectal Cancer Patients. J Cancer Sci Ther 9: 683-689. doi:10.4172/1948-5956.1000492

56. Barras D (2015) BRAF Mutation in Colorectal Cancer: An Update. Biomarkers Cancer 7: 9-12.

57. Dallol A, Buhmeida A, Al-Ahwal MS, Al-Maghrabi J, Bajouh O, et al. (2016) Clinical significance of frequent somatic mutations detected by highthroughput targeted sequencing in archived colorectal cancer samples. J Transl Med 14: 118

58. Castellano E, Downward J (2011) RAS Interaction with PI3K: More than just another effector pathway. Genes Cancer 2: 261-274.

59. Iqbal N, lqbal N (2014) Human epidermal growth factor receptor 2 (HER2) in cancers: Overexpression and Therapeutic Implications. Mol Biol Int 2014 852748.

60. Shabbir A, Mirza T, Khalid AB, Qureshi MA, Asim SA (2016) Frequency of Her2/neu expression in colorectal adenocarcinoma: A study from developing South Asian Country. BMC Cancer 1: 855 